\title{
Detection of Brucella melitensis in bovine milk and milk products from apparently healthy animals in Egypt by real-time PCR
}

\author{
Gamal Wareth ${ }^{1,2,3}$, Falk Melzer ${ }^{1}$, Mandy C Elschner ${ }^{1}$, Heinrich Neubauer ${ }^{1}$, Uwe Roesler $^{2}$ \\ ${ }^{1}$ Friedrich-Loeffler-Institut, Federal Research Institute for Animal Health, Institute of Bacterial Infections and \\ Zoonoses, Jena, Germany \\ 2 Institute of Animal Hygiene and Environmental Health, Free University of Berlin, Berlin, Germany \\ ${ }^{3}$ Department of Pathology, Faculty of Veterinary Medicine, Benha University, Qalyobia, Egypt
}

\begin{abstract}
Introduction: Brucellosis in Egypt is an endemic disease among animals and humans. In endemic developing countries, dairy products produced from untreated milk are a potential threat to public health. The aim of this study was to detect brucellae in milk and milk products produced from apparently healthy animals to estimate the prevalence of contamination.

Methodology: Two hundred and fifteen unpasteurized milk samples were collected from apparently healthy cattle $(\mathrm{n}=72)$ and buffaloes $(\mathrm{n}=$ 128) reared on small farms, and from milk shops $(n=15)$ producing dairy products for human consumption. All milk samples were examined by indirect enzyme-linked immunosorbent assay (iELISA) and real-time PCR (RT-PCR) to detect Brucella antibodies and Brucella-specific DNA, respectively.

Results: Using iELISA, anti-Brucella antibodies were detected in 34 samples (16\%), while RT-PCR amplified Brucella-specific DNA from 17 milk samples (7.9\%). Species-specific IS711 RT-PCR identified 16 of the RT-PCR-positive samples as containing $B$. melitensis DNA; 1 RT-PCR-positive sample was identified as containing B. abortus DNA.

Conclusions: The detection of Brucella DNA in milk or milk products sold for human consumption, especially the highly pathogenic species B. melitensis, is of obvious concern. The shedding of Brucella spp. in milk poses an increasing threat to consumers in Egypt. Consumption of dairy products produced from non-pasteurized milk by individual farmers operating under poor hygienic conditions represents an unacceptable risk to public health.
\end{abstract}

Key words: Brucella melitensis; bovine; unpasteurized milk and milk products; iELISA; RT-PCR.

J Infect Dev Ctries 2014; 8(10):1339-1343. doi:10.3855/jidc.4847

(Received 14 February 2014 - Accepted 07 August 2014)

Copyright (C) 2014 Wareth et al. This is an open-access article distributed under the Creative Commons Attribution License, which permits unrestricted use, distribution, and reproduction in any medium, provided the original work is properly cited.

\section{Introduction}

Brucellosis is a highly contagious bacterial disease of zoonotic importance, causing significant reproductive losses in animals. Members of the genus Brucella are Gram-negative, facultative intracellular pathogens that may affect a wide range of mammals including humans, cattle, sheep, goats, pigs, rodents, and marine mammals [1]. Despite the implementation of the National Brucellosis Control Program in Egypt 32 years ago [2], the disease is still endemic among ruminants and humans [3]. Recently, concurrent infections with acute febrile illness (AFI) of unknown cause have been reported as a common clinical syndrome among patients seeking hospital care in Egypt [4]. Of these patients, 5\% are culture-positive for Brucellae and $11 \%$ show positive results by serological testing [5]. The total seroprevalence of human brucellosis ranges between $5 \%$ and $8 \%$, with no significant effect of seasonal variation [6]. Furthermore, there are reports suggesting that the incidence of human infection may be increasing in these and other populations in Egypt $[4,7,8]$. Brucellosis is an occupational disease that affects individuals who have close contact with infected animals, such as veterinarians, abattoir workers, farmers, and laboratory personnel. Ingestion of unpasteurized milk and dairy products made from this source may expose humans to pathogenic Brucella species, and is a common route of infection in humans $[9,10]$. In particular, immunocompromised persons, including the elderly, pregnant women, infants and young children, are at the highest risk of contracting brucellosis [11]. In dairy animals, Brucella spp. replicate in the mammary gland and supra-mammary lymph nodes, and these animals continually excrete the pathogen into milk throughout their lives [12]. 
Since cow and buffalo milk and milk products are more commonly consumed than the milk of sheep, goats and camels in Egypt, the risk for human infection is mainly confined to cattle and buffaloes [13]. In Egypt and other developing countries, dairy products such as butter, fermented milk, Kareish cheese, and yogurt may be produced from unpasteurized milk collected by individual farmers operating small farms in substandard sanitary conditions. It has also been shown that $B$. melitensis can survive in naturally contaminated unpasteurized milk for up to five days when kept at $4{ }^{\circ} \mathrm{C}$ and up to nine days at $-20^{\circ} \mathrm{C}$ [14]. In yogurt stored at ambient temperature and at $4^{\circ} \mathrm{C}$, Brucella organisms can survive four and eight days, respectively. In Kareish cheese manufactured from naturally contaminated unpasteurized milk, the Brucella survival rate increased until the eighth day at ambient temperature [14]. Therefore, the occurrence of Brucella spp. in these products is to be expected.

This preliminary study was performed to assess the presence of brucellae in fresh milk samples and untreated dairy products (e.g., yogurt), using iELISA and RT-PCR

\section{Methodology}

A total of 215 raw or unpasteurized milk samples were collected from apparently healthy cows $(n=72)$ and buffaloes $(\mathrm{n}=128)$ at small farms, and from milk shops $(n=15)$ that produce dairy products for human consumption. From milk shops, 5 samples were collected from milk tanks, 6 from yogurt, and 4 from cream. All samples were collected from neighboring localities in Menufiya, Qalyobia, and Sharkia governorates of the Delta region, Egypt. These areas are known to be endemic for brucellosis. Cattle and buffaloes are reared there to produce milk for consumption in large cities such as Cairo. Indirect enzyme-linked immunosorbent assay (iELISA) was performed on all milk samples using Brucella smooth lipopolysaccharide (S-LPS) as the antigen (IDEXX, Montpellier SAS, France). The iELISA results were classified as positive or negative using the cutoff values recommended by the manufacturer.

DNA was extracted from milk, cream, and yogurt samples using the High Pure PCR Template Preparation Kit (Roche Applied Sciences, Mannheim, Germany) according to the manufacturer's instructions. RT-PCR assays were used to confirm the presence of the genus Brucella and to identify $B$. abortus and $B$. melitensis in the extracted DNA samples. Assays were performed in single runs for genus and species identification as described previously by Probert et al. [15]. All samples were tested in duplicate; cycle threshold (ct) values below 40 cycles were interpreted as positive.

\section{Results}

As shown in Table 1, 38 milk samples were positive in at least one test and 177 samples were negative either with iELISA or PCR assay for Brucella. The iELISA detected Brucella antibodies in 18, 13 and 3 milk samples from cows, buffaloes and milk tanks, respectively. Genus-specific bcsp31 PCR amplified Brucella-specific DNA from 9, 7 and 1 milk samples obtained from cows, buffaloes and a milk tank, respectively. Species-specific IS711 RT-PCR confirmed the presence of $B$. abortus-specific DNA in 1 cow milk sample, while in 16 samples, B. melitensisspecific DNA was detected. In 18, 17 and 3 milk samples from cows, buffaloes and milk tanks in dairy shops, respectively, Brucella antibodies and/or Brucella-specific DNA were detected. All cream and yogurt samples were negative.

\section{Discussion}

Brucellosis remains an endemic disease of ruminants and humans in most Middle Eastern countries and in various countries of the Mediterranean basin [2]. Recently, brucellosis cases have increased sharply in persons living in areas located far away from Brucella-endemic areas. Brucellosis can also be easily transmitted from endemic rural pockets to non-endemic urban areas [16]. The explanation for this is in part may be that raw milk and dairy products of animals infected with Brucella are now being transported over very long distances and consumed by an at-risk population. In Egypt, huge investments in surveillance and eradication of brucellosis were made in the last 25 years with only limited success. Endemic countries suffer from loss of productivity and an adverse impact on human health [1].

Isolation and phenotyping of Brucella is still the gold standard for diagnosis, but it is time consuming, potentially hazardous, and requires well-trained personnel [17]. Molecular diagnosis of brucellosis by PCR techniques has increasingly been used as a supplementary method [18,19]. Genus-specific PCR assays are inexpensive tests for screening and have the capability to detect low concentrations of DNA. Our findings are completely in agreement with previous reports that $B$. melitensis DNA can be amplified from bovine milk samples [20]. 
Table 1. iELISA and PCR results of milk samples showing a positive result in at least one test.

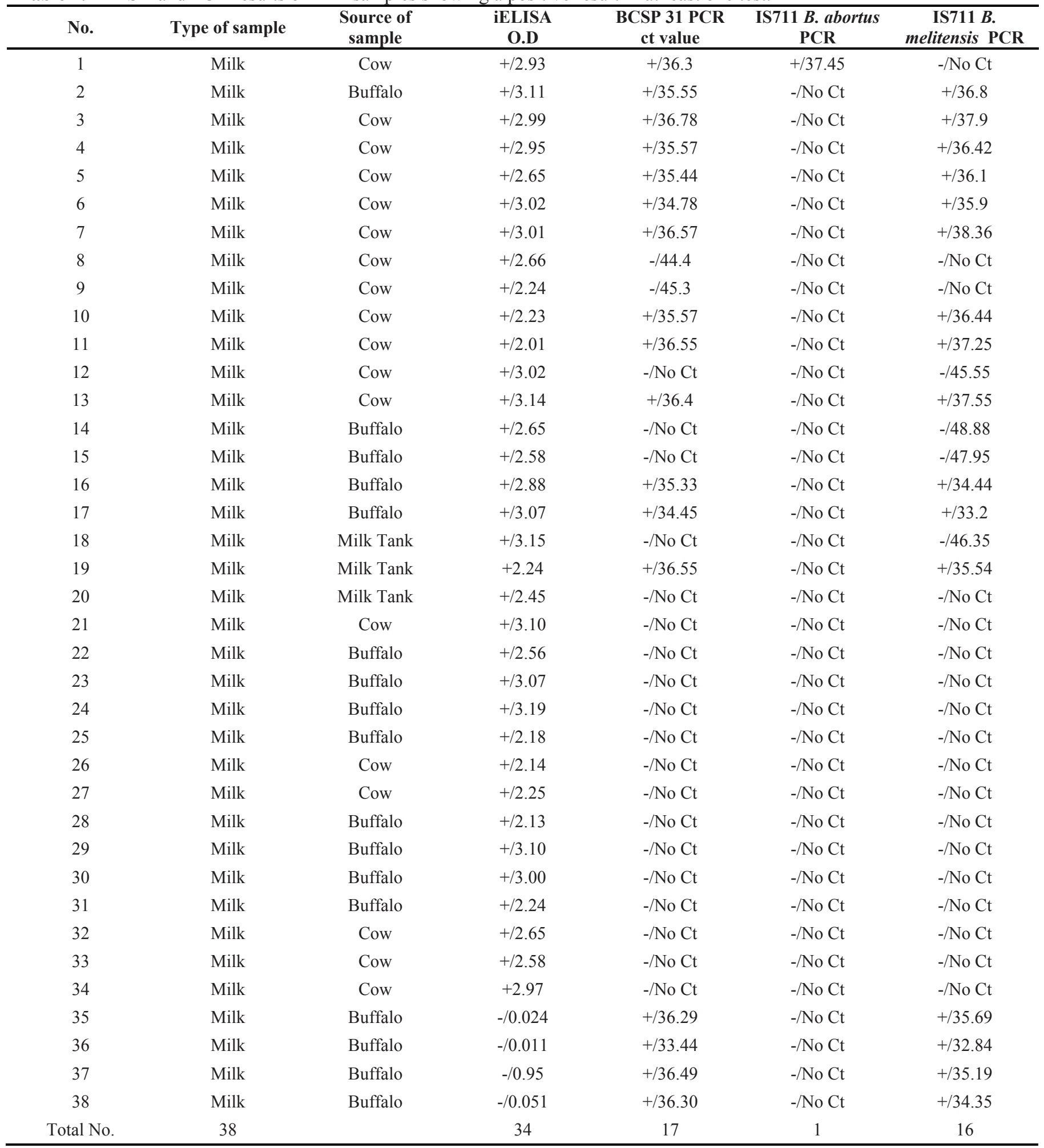

ELISA-positive samples showing cutoff values $(\geq 2)$

PCR-positive samples showing ct value $(\mathrm{ct} \leq 40)$ 
Our data show that these assays can be used for risk analysis investigation during routine control of milk, especially as they were able to detect Brucella DNA in ELISA-negative samples. Failure of PCR in ELISA positive milk samples can be explained by the fact that antibody titers remain elevated for a long time after infection, independent of circulating bacteria or DNA. However, false positive ELISA results due to crossreactions with the LPS of other bacteria (e.g., Yersinia enterocolitica $\mathrm{O}: 9$ ) would coincide with true negative PCR results. Yersinia enterocolitica is known to be widespread in dairy herds worldwide, but its prevalence in Egyptian cattle herds is unknown. Further investigations are needed to illuminate the true cause of these findings. Failure of PCR to detect Brucella DNA in cheese or yogurt might be explained by the fact that these products were indeed not contaminated or simply by the fact that the purification method used by us was inadequate for these matrices. A more dedicated study is needed to determine the risk for the consumer posed by these foods.

Mastitis in animal brucellosis is uncommon, but persistent infection of the udder accompanied by intermittent shedding of the organism in milk has been reported [21]. Cows infected with B. abortus usually abort only once, and following that give birth to healthy or weak calves. Some cows may not exhibit any clinical signs of the disease and give birth to healthy calves [22]. Those animals can be the source of continual infection [23]. In infected herds, RT-PCR may be a very valuable tool in reducing the time to eradicate the disease by identifying anergic shedders or newly infected animals that should be removed from the herds immediately. B melitensis is one of the major causes of abortion in small ruminants; other ruminants may be infected occasionally [24]. It is also the main agent responsible for brucellosis in humans, as it is highly virulent for humans. Circulation of this species in untypical hosts like cattle or buffaloes is of special concern to public health; control or eradication programs have to be adapted to this special situation accordingly. As such, species-specific PCRs are valuable tools in screening programs to identify the prevalent Brucella species.

Transmission of Brucella through contaminated milk and milk products is an increasing threat not only for individuals, but also for whole families in urban and rural settings of endemic countries [25]. In these areas, trade of non-pasteurized fresh milk and raw dairy products should be strictly controlled and limited to certified Brucella-free farms. Our data show that PCR is a sensitive tool for the control of brucellosis in raw milk. Basic health education with respect to the nature of the disease and the modes of transmission through milk products is required for local farmers and consumers. Additionally, a traditional belief that raw milk is better than pasteurized milk must be addressed in light of the current scientific information.

\section{Conclusions}

Consumption of potentially contaminated raw milk and unpasteurized dairy products is a serious risk with great public health significance. General health education on the nature of the disease and the modes of transmission through milk products is generally required to avoid infection or spread of the pathogens.

\section{Acknowledgements}

We gratefully acknowledge Ahmed Hikal for providing help in sample collection. We would further like to thank the DAAD (German Academic Exchange Service) for financial support of G.W., grant no. A/11/92495 and the Egyptian Ministry of Higher Education for partially funding. The funders had no role in study design, data collection and analysis, decision to publish, or preparation of the manuscript.

\section{References}

1. Cutler SJ, Whatmore AM, Commander NJ (2005) Brucellosis - new aspects of an old disease. J Appl Microbiol 98: 12701281.

2. Refai M (2002) Incidence and control of brucellosis in the Near East region. Vet Microbiol 90: 81-110.

3. Holt H, Eltholth M, Hegazy Y, El-Tras W, Tayel A, Guitian J (2011) Brucella spp. infection in large ruminants in an endemic area of Egypt: Cross-sectional study investigating seroprevalence, risk factors and livestock owner's knowledge, attitudes and practices (KAPs). BMC Public Health 11: 341350.

4. Parker T, Murray C, Richards A, Samir A, Ismail T, Fadeel M, Jiang J, Wasfy M, Pimentel G (2007) Concurrent infections in acute febrile illness patients in Egypt. Am J Trop Med Hyg 77: 390-392.

5. Crump JA, Youssef FG, Luby SP, Wasfy MO, Rangel JM, Taalat M, Oun SA, Mahoney FJ (2003) Estimating the incidence of typhoid fever and other febrile illnesses in developing countries. Emerg Infect Dis 9: 539-544.

6. Samaha H, Mohamed TR, Khoudair RM, Ashour HM (2009) Serodiagnosis of brucellosis in cattle and humans in Egypt. Immunobiology 214: 223-226.

7. Jennings GJ, Hajjeh RA, Girgis FY, Fadeel MA, Maksoud MA, Wasfy MO, El-Sayed N, Srikantiah P, Luby SP, Earhart K, Mahoney FJ (2007) Brucellosis as a cause of acute febrile illness in Egypt. Trans R Soc Trop Med Hyg 101: 707-713.

8. Mohammad K, El Ghazaly M, Zaalouk T, Morsy A (2011) Maternal brucellosis and human pregnancy. J Egypt Soc Parasitol 41: 485-496.

9. Al-Dahouk S, Nöckler K, Hensel A, Tomaso H, Scholz HC, Hagen RM, Neubauer H (2005) Human brucellosis in a nonendemic country: a report from Germany, 2002 and 2003. Eur J Clin Microbiol Infect Dis 24: 450-456. 
10. El-Mohammady H, Shaheen H, Klena J, Nakhla I, Weiner M, Armstrong A (2012) Specific IgA antibodies in the diagnosis of acute brucellosis. J Infect Dev Ctries 6: 192-200. doi: $10.3855 /$ jidc. 1411 .

11. Committee on Infectious Diseases; Committee on Nutrition; American Academy of Pediatrics (2014) Consumption of raw or unpasteurized milk and milk products by pregnant women and children. Pediatrics 133: 175-179.

12. Refai M (2003) Application of biotechnology in the diagnosis and control of brucellosis in the Near East Region. World $\mathrm{J}$ Microbiol Biotechnol 19: 443-449.

13. Refai M (1989) Brucellosis in Egypt and its control. J Egypt Vet Med Ass 49: 801-808.

14. Samaha HAM (2008) Viability of Brucella melitensis biovar 3 , in milk and some dairy products. Egyptian Journal of Medical Microbiology 17: 179-185.

15. Probert WS, Schrader KN, Khuong NY, Bystrom SL, Graves MH (2004) Real-time multiplex PCR assay for detection of Brucella spp., B. abortus, and B. melitensis. J Clin Microbiol 42: 1290-1293.

16. Pappas G, Panagopoulou P, Christou L, Akritidis N (2006) Brucella as a biological weapon. Cell Mol Life Sci 63: 22292236.

17. Alton GG, Jones LM, Angus RD, Verger JM (1988) Techniques for the brucellosis laboratory. Paris: Institut National de la Recherche Agronomique. 190 p.

18. Leal-Klevezas D, Martinez-Vazquez I, Lopezmerino A, Martinez-Soriano J (1995) Single step PCR for detection of Brucella spp. from blood and milk of infected animals. J Clin Microbiol 33: 3087-3090.

19. Guarino A, Serpe L, Fusco G, Scaramuzzo A, Gallo P (2000) Detection of Brucella species in buffalo whole blood by genespecific PCR. Vet Rec 147: 634-636.
20. Hamdy MR, Amin AS (2002) Detection of Brucella species in the milk of infected cattle, sheep, goats and camels by PCR. Vet J 163: 299-305.

21. Tittarelli M, Di Ventura M, De Massis F, Scacchia M, Giovannini A, Nannini D, Caporale V (2005) The persistence of Brucella melitensis in experimentally infected ewes through three reproductive cycles. J Vet Med B Infect Dis Vet Public Health 52: 403-409.

22. Xavier MN, Costa ÉA, Paixão TA, Santos RL (2009) The genus Brucella and clinical manifestations of brucellosis. Ciência Rural 39: 2252-2260.

23. Díaz Aparicio E (2013) Epidemiology of brucellosis in domestic animals caused by Brucella melitensis, Brucella suis and Brucella abortus. Rev Sci Tech 32: 43-51.

24. Blasco J, Molina-Flores B (2011) Control and eradication of Brucella melitensis infection in sheep and goats. Vet Clin North Am Food Anim Pract 27: 95-104.

25. Chen S, Zhang H, Liu X, Wang W, Hou S, Li T, Zhao S, Yang Z, Li C (2014) Increasing threat of brucellosis to lowrisk persons in urban settings, china. Emerg Infect Dis 20: 126-130.

\section{Corresponding author}

Gamal Wareth

Friedrich-Loeffler-Institut, Federal Research Institute for Animal

Health

Institute of Bacterial Infections and Zoonoses

Naumburger Str. 96a, 07743 Jena, Germany

Phone: +49 015779564050

Email: gamalwareth@hotmail.com; gamal.wareth@fli.bund.de

Conflict of interests: No conflict of interests is declared. 